\title{
How to treat diminutive polyps? Do we need more evidence?
}

Author

Institution
James E. East

Translational Gastroenterology Unit, John Radcliffe Hospital, Oxford, United Kingdom
Bibliography

Dol http://dx.doi.org/

10.1055/s-0034-1391364

Published online: 3.2.2015

Endoscopy International Open

2015; 03: E81-E82

(c) Georg Thieme Verlag KG

Stuttgart $\cdot$ New York

E-ISSN 2196-9736

\section{Corresponding author}

\section{James E. East, MD (Res) FRCP}

Translational Gastroenterology Unit

Experimental Medicine Division Nuffield Department of Clinical Medicine

University of Oxford John Radcliffe Hospital Headley Way, Headington Oxford, OX3 9DU

United Kingdom

Fax: +4401865 228763

jameseast6@yahoo.com
The question of whether we manage polyps effectively has come to prominence because of the rates of interval or post-colonoscopy colorectal cancers, which range from $2.5 \%$ to $10.7 \%$ and which may in part be due to a failure to resect polyps completely (radically) [1,2]. This issue was highlighted in the recently reported CARE (Complete Adenoma REsection) study of polyps 5 to $20 \mathrm{~mm}$ in size, which reported an overall rate of incomplete resection of $10 \%$ [3]. However, the vast majority of polyps resected at colonoscopy $(80 \%)$ are $5 \mathrm{~mm}$ or smaller in size [4]. Although the rate of advanced disease on a per-polyp basis is low, the fact that small polyps are so common means that the absolute number of small polyps harboring advanced disease is comparable with the number of larger (6- to 9-mm) polyps [5]. It is therefore possible that a reasonable percentage of interval cancers arise in diminutive polyps that have been nonradically, partially resected [2]. These lesions have traditionally been considered low risk, and therefore low risk methods to resect them - that is, cold techniques - have increasingly been favored. Hot biopsy is more difficult to justify, given the risks for bleeding and late perforation and the supportive data against hot biopsy derived from animal models [6,7]. There is also a requirement to retrieve tissue for pathology to allow a determination of correct surveillance intervals; however, retrieving small polyps is a challenge, and the use of hot techniques can lead to tissue destruction, rendering pathologic assessment impossible.

Optical biopsy may help here because a diagnosis is potentially available for $100 \%$ of detected polyps, whereas $17 \%$ of small and diminutive lesions may be lost or destroyed $[8,9]$. Recent European Society of Gastrointestinal Endoscopy guidelines support the limited use of optical biopsy for diminutive polyps in controlled circumstances and in expert hands, but communitybased data suggest that this approach is not yet suitable for widespread implementation $[8,10]$. Therefore, one option in expert hands may be not to treat some of these lesions at all and to leave them in situ, avoiding issues of resection risk, retrieval, and pathologic assessment as well as reducing costs-the DISCARD (Detect InSpect ChAracterise Resect and Discard) strategy [9], endorsed in the American Society for Gastrointestinal Endoscopy PIVI (Preservation and Incorporation of Valuable Endoscopic Innovations) statement [11].

Nevertheless, the majority of lesions proximal to the rectosigmoid do require resection. If we reject hot biopsy as too dangerous, as many have done, then the remaining three methods are cold forceps polypectomy, cold snaring, and hot snaring. Gómez and colleagues present pilot data in this issue of Endoscopy International Open, looking at the effectiveness of a CARE type of study, in which the resection beds of diminutive lesions are analyzed for residual polyp [12]. The fact that such a pilot study has been performed and reported is a testament to the maturity developing in endoscopic research trial design, in which a controlled, stepwise approach is adopted to establish feasibility and highlight potential pitfalls before larger definitive trials are undertaken. The Mayo team members are to be congratulated on this. Specifically, they observe that for most endoscopists, cold endoscopic mucosal resection of the polyp base after polypectomy is not feasible, and that biopsy of the edge of the base is more feasible.

The trial team had two main aims. The first was to demonstrate the feasibility of recruiting patients into a polypectomy trial with an outcome measure of completeness of polypectomy, in which they would be randomized to one of three methods of polypectomy. With 60 patients included at baseline, 62 polyps were randomized and resected from 37 patients. The study team does not state how many patients had to be approached before 60 patients were recruited, which is an im- 
portant consideration. No patients reported harm from the procedure at 30 days. Therefore, a larger trial with this methodology seems viable.

The second aim was to collect data on the rate of incomplete resection to support a power calculation for the main study. Here, the authors found that 5 of 60 polyps ( $8 \%$; $95 \% \mathrm{CI} 3 \%-19 \%$ ) had residual tissue in the polyp base; however, this was not evenly distributed. None of 20 hyperplastic polyps showed residual tissue, whereas 3 of 31 adenomas (10\%) and 2 of 4 sessile serrated adenomas (50\%) had residual tissue. Of the polyps, $89 \%$ were classified as sessile and $11 \%$ as flat, presumably based on the Paris classification, although this is not explicitly stated. There has been recent concern about the validity of the Paris classification, with only "moderate" inter-observer agreement among experts $(\mathrm{K}=0.42$ ) for all polyps; agreement is worse for diminutive polyps, with a $\mathrm{k}$ value of 0.27 ("fair") [13]. This may be relevant for diminutive polyps, in which tissue grip may be better on the steeper sides of a sessile lesion.

There are a number of interesting findings in this small data set: that residual neoplastic tissue is as common as was seen in the CARE study, and that serrated lesions seem to be at greater risk for residual tissue than adenomas, although the numbers are very limited. It is also striking that none of the 20 hyperplastic polyps showed residual tissue. Again, this may reflect the small number but sits in stark contrast to the high rates for sessile serrated adenomas. The failure of cold forceps polypectomy with multiple bites in polyps up to $5 \mathrm{~mm}$ in size is unsurprising, and a salutary lesson is that resection with this technique generally should be limited to polyps that can be completely engulfed in the cups of the biopsy forceps in a single bite - that is, polyps less than $2.8 \mathrm{~mm}$ in size $[7,14]$. However, the failure of cold snaring despite optimal technique, with a small rim of normal tissue left, is more surprising and suggests that we may also need to review this technique as more data become available. This is in the context of endoscopists feeling that they could not see residual tissue in polyp bases when they used modern high resolution and high definition colonoscopes.

Does this pilot study lead to any conclusions regarding the question posed in the title of this editorial: do we need still more evidence? Undoubtedly, yes. Like the best research, this pilot study raises more questions than it was expected to answer, suggesting that residual tissue after the resection of diminutive polyps may be at least as important as it is in the larger, 5 - to 20-mm polyps described in the CARE study. A larger study involving multiple operators and ideally conducted at multiple centers is needed, and these data demonstrate that such a study is feasible. In an ideal world, such a study would also involve longer-term followup to discover what happens to incompletely resected lesion sites and to see if important dysplasia recurs in the colonic segments in which incomplete (nonradical) resection is proven. The safety of hot snaring techniques will also be a key issue, especially in the right side of the colon. In the era of heroic endoscopic mucosal resection and endoscopic submucosal dissection, the resection of diminutive polyps has become something of a Cinderella topic. This pilot study suggests that diminutive polyps must also come to the ball.

Competing interests: Advisory board: Cosmo technologies. Speaker: Abbvie, Olympus. Research funding: Olympus, Cosmo Technologies.

\section{References}

1 Morris EJ, Rutter MD, Finan PJ et al. Post-colonoscopy colorectal cancer (PCCRC) rates vary considerably depending on the method used to calculate them: a retrospective observational population-based study of PCCRC in the English National Health Service. Gut In press 2014: doi: DOI 10.1136/gutjnl-2014-308362

2 le Clercq CM, Bouwens MW, Rondagh EJ et al. Postcolonoscopy colorectal cancers are preventable: a population-based study. Gut 2014; 63: 957-963

3 Pohl H, Srivastava A, Bensen SP et al. Incomplete polyp resection during colonoscopy-results of the complete adenoma resection (CARE) study. Gastroenterology 2013; 144: 74-80

4 Chen SC, Mouchli A, Chadalawada V et al. Histopathology of Small Polyps Removed in the Videoendoscopic Era [abstract]. Gastrointest Endosc 2006; 63: AB199

5 Lieberman D, Moravec $M$, Holub J et al. Polyp size and advanced histology in patients undergoing colonoscopy screening: implications for CT colonography. Gastroenterology 2008; 135: 1100-1105

6 Metz AJ, Moss A, McLeod D et al. A blinded comparison of the safety and efficacy of hot biopsy forceps electrocauterization and conventional snare polypectomy for diminutive colonic polypectomy in a porcine model. Gastrointest Endosc 2013; 77: 484-490

7 East JE. Resection Techniques for Small Colonic Polyps: Cold Forceps Polypectomy, Hot Biopsy, Cold Snare and Hot Snare. Video Journal and Encyclopedia of GI Endoscopy 2013; 1: 401-402 Available from: http://www.video-endoscopy.com/article/S2212-0971(13)70178-X/ fulltext Accessed 11 December 2014

8 East JE, Leedham SJ. Colonoscopy, tumors. Endoscopy 2014; 46: 318 321

9 Ignjatovic A, East JE, Suzuki N et al. Optical diagnosis of small colorectal polyps at routine colonoscopy (Detect InSpect ChAracterise Resect and Discard; DISCARD trial): a prospective cohort study. Lancet Oncol 2009; 10: $1171-1178$

10 Kaminski MF, Hassan C, Bisschops $R$ et al. Advanced imaging for detection and differentiation of colorectal neoplasia: European Society of Gastrointestinal Endoscopy (ESGE) Guideline. Endoscopy 2014; 46: $435-449$

11 Rex DK, Kahi C, O'Brien M et al. The American Society for Gastrointestinal Endoscopy PIVI (Preservation and Incorporation of Valuable Endoscopic Innovations) on real-time endoscopic assessment of the histology of diminutive colorectal polyps. Gastrointest Endosc 2011; 73: $419-422$

12 Gómez V, Badillo RJ, Crook JE et al. Diminutive colorectal polyp resection comparing hot and cold snare and cold biopsy forceps polypectomy. Results of a pilot randomized, single-center study. Endoscopy International Open In press 2014: doi: DOI 10:1055/s-0034-1390789

13 van Doorn SC, Hazewinkel Y, East JE et al. Polyp morphology: an interobserver evaluation for the Paris classification among international experts. Am J Gastroenterol In press 2014: DOI 10:1038/ajg.2014.326

14 Efthymiou M, Taylor AC, Desmond PV et al. Biopsy forceps is inadequate for the resection of diminutive polyps. Endoscopy 2011; 43: 312 -316 